\title{
Study on Dual-Rotor Permanent Magnet Induction Motor and Performance
}

\author{
Tongshan Diao*
}

School of Electrical Engineering and Automation, Qilu University of Technology, Jinan, Shandong, 250353, P.R. China

\begin{abstract}
In this paper, dual-rotor permanent magnet induction motor(DRPMIM) is studied to improve performance of usual induction motor(IM). Two-dimensional finite element model for DRPMIM is established by Maxwell Ansoft software, and electromagnetic characters of that was analyzed.Based on the rotating coordinate system, the mathematical model concerning DRPMIM, performance curves under the different load are obtained. The final simulation analysis results are in good agreement with the theoretical predicting results, which can be used to afford a theoretical basis to design the DRPMIM in the future. Compared with the conventional asynchronous motor, the DRPMIM can effectively improve power factor and efficiency.
\end{abstract}

Keywords: Dual-rotor permanent magnet induction motor (DRPMIM), electromagnetic field, finite element method (FEM), mathematical model, simulation.

\section{INTRODUCTION}

The three phrase induction motors (IM)are widely used in modern industry due to their robustness, rugged cheap design and maintenance free compared to other solution such as synchronous motors. Motors for pumps, fans, and compressors, which must be driven for a long time, require high efficiency [1-5]. However, IM has two disadvantages, poor power factor and low efficiency. For improvement of the performances, by adding permanent magnet to the IM design, several mechanical configurations can be used in the IM. The magnet rotor can be placed either inside the squirrel cage rotor, between the main rotor and stator, or outside the stator. Each of these configurations will influence the machine characteristics in a different way. By placing the magnet rotor inside the original rotor, only the rotor's parameters will be changed, leaving the parameters of the stator unchanged. A reduction in the rotor yoke will decrease the value of the rotor leakage reactance. This in turn will influence the torque-speed profile of the machine [6-10]. By placing the magnet rotor between the stator and rotor, both the stator and rotor characteristics will be changed. Either a larger stator or a smaller rotor is now needed. To match the performance of the ordinary IM, this will result in a larger diameter machine to realize the same power output. By placing the magnet rotor on the outside, the stator yoke is basically removed, reducing the stator leakage reactance to some extent [11]. proposes a new type of induction motor that has free rotating magnets inside the rotor (DRPMIM).

Fig. (1) shows the typical DRPMIM where the machine topology with one stator and two rotors is adopted. Two rotors, outer cage rotor and inner permanent magnet rotor

*Address correspondence to this author at the School of Electrical Engineering and Automation, Qilu University of Technology, Jinan, Shandong, 250353, P.R. China; Tel: +86 15964023908; Fax: +86 86385070; E-mail: 2019013571@qq.com usually have different speed and torque. This type of machine can be as a combination of permanent magnet synchronous motor and conventional induction motor, and high performance may be achieved because permanent magnet excitation would contribute to a decrease in the magnetizing current in the stator [12-17].

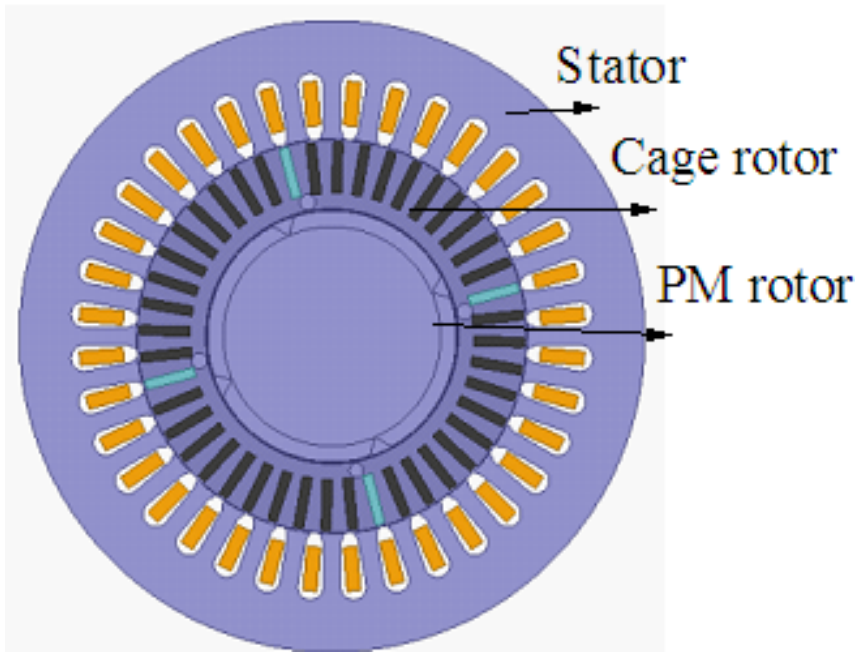

Fig. (1). Typical DRPMIM topology structure.

Relatively little literature exists on the DRPMIM research.

Main purpose of this article is to verify the performances of DRPMIM. Its dynamic mathematical model is established, which is convenient for controlling it.The paper is organized as follows. Section II depicts the operation principle of the DRPMIM. In Section III, based on FEM, the model of DRPMIM were established and electromagnetic characters of that was analyzed by Maxwell Ansoft software. Section IV the dynamic mathematical model of DRPMIM is presented. In Section V, simulation results on DRPMIM are 
provided, and finally, conclusions are drawn in Section VI. Simulation studies are carried out to verify the proposed model.

\section{STRUCTURE AND OPERATION PRINCIPLE}

Fig. (2) shows the cross-section of the DRPMIM where stator is omitted. Two rotors, inner permanent magnet and outer cage rotor, rotate at the speed which is independent each other. The stator has the same structure as that of a conventional induction motor. As the stator windings are directly connected with three alternating current, which generates rotating magnetic field. The cage rotor fixed to the shaft revolves slower than the synchronized speed of the rotating magnetic field by the stator current. The magnets rotor, however, revolves at synchronized speed [18-20].

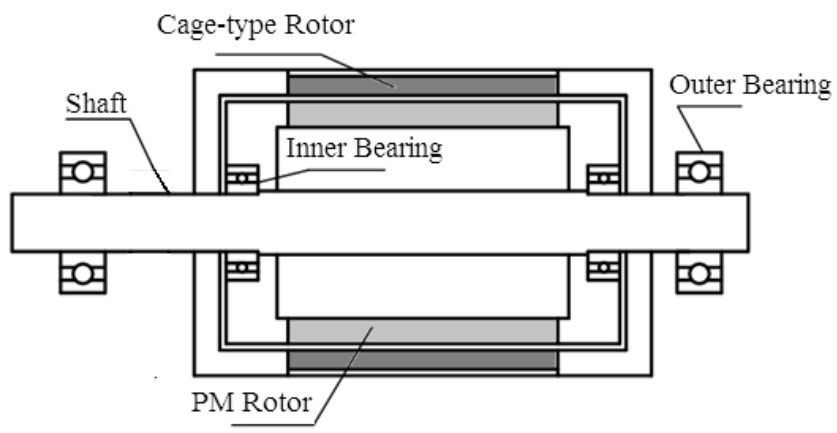

Fig. (2). Cross-sectional view of the DRPMIM (stator is omitted).

\section{FINITE ELEMENT ANALYSIS}

\subsection{Establishment of the Finite Element Model}

The model of DRPMIM were established and analyzed by Maxwell software, in order to compare the differences with usual IM.A time-step finite element was adapted to analyze the electromagnetic characteristics of DRPMIM. The geometry of the DRPMIM discussed in this paper is as shown in Fig. (1). Rated voltage is $380 \mathrm{~V}$, rated speed is $1000 \mathrm{r} / \mathrm{min}$, permanent magnet is made of $\mathrm{Nd}-\mathrm{Fe}-\mathrm{B}$, driving power is direct current power supply, and the surface mounted magnets shape and radial magnetization. Residual flux density is $1.04 \mathrm{~T}$, coercive force $H_{\mathrm{c}}$ is $890 \mathrm{kA} / \mathrm{m}$, stator slot number is 36 , pole pairs is 2 . The other main technical parameters of motors are shown in Table 1.

Table 1. Parameters of prototype.

\begin{tabular}{|c|c|c|c|}
\hline Parameters & lues (mm) & Parameters & Values $(\mathrm{mm})$ \\
\hline Outer diameter of stator & 160 & \multicolumn{2}{|c|}{ Inside diameter of PM rotor 39} \\
\hline Inner diameter of stator & 100 & Inner air-gap & 0.25 \\
\hline Outer diameter of cage rotor & or 99 & Outer air-gap & 0.3 \\
\hline Inside diameter of cage rotor & or 64.6 & Thickness of PM & 6 \\
\hline Outer diameter of PM rotor & or 64 & Stack length $\mathrm{L}_{\mathrm{Fe}}$ & 100 \\
\hline
\end{tabular}

\subsection{Theoritical Analysis of the Electromagnetic Field}

The FE mesh is automatically generated for the calculation of magnetic flux, flux density, and force distributions. The boundary is filled with vacuum with double size of the objects of the FE model.

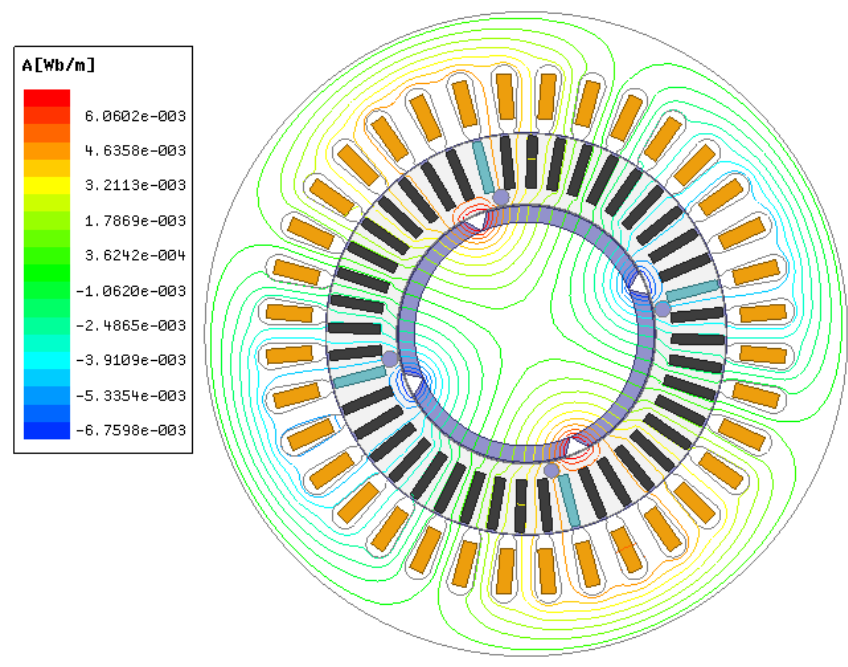

(a) DRPMIM

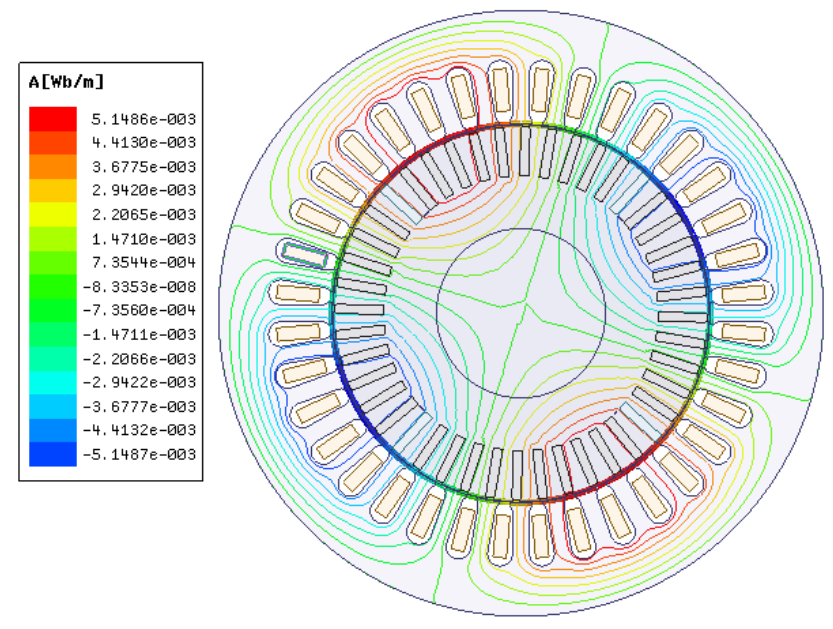

(b) IM

Fig. (3). Distribution of magnetic line.

Both the cogging torque and the starting curves are computed via FE analysis, and the starting curves are compared with that of the IM in following sections. The model for the 2-D FE flux lines of DRPMIM is illustrated in Fig. (3), and the starting curves and the cogging torque curves are shown in Figs. $(4,5)$, respectively.

The two type of motors are simulated in the no-load state, and distribution of magnetic line is obtained, as shown in Fig. (3). The Fig. (3a) shows distribution of magnetic line for DRPMIM and Fig. (3b) shows distribution of magnetic line for IM. They show that the magnetic line of force is positive extreme, the magnetic line of force is negative extreme and there is flux leakage in stator slots, which determine flux density of air-gap magnetic, in order to afford a theoretical basis to analyze the cogging torque and mathematical model for DRPMIM. From the Fig. (3), we can see amplitude the magnetic line of DRPMIM is larger than that of IM. There are free rotating magnets inside the cage rotor, which increase magnetic flux linkage.

Fig. (4) shows the speed variation along with the time. The figure illustrates that the speed curves of cage rotor and PM rotor is nearly the same in the steady state, which is 
under no load.Because the PM rotor is not load and its weight is light, so the torque ripple is a bit large. The speed curve of IM is relatively stable under no load.

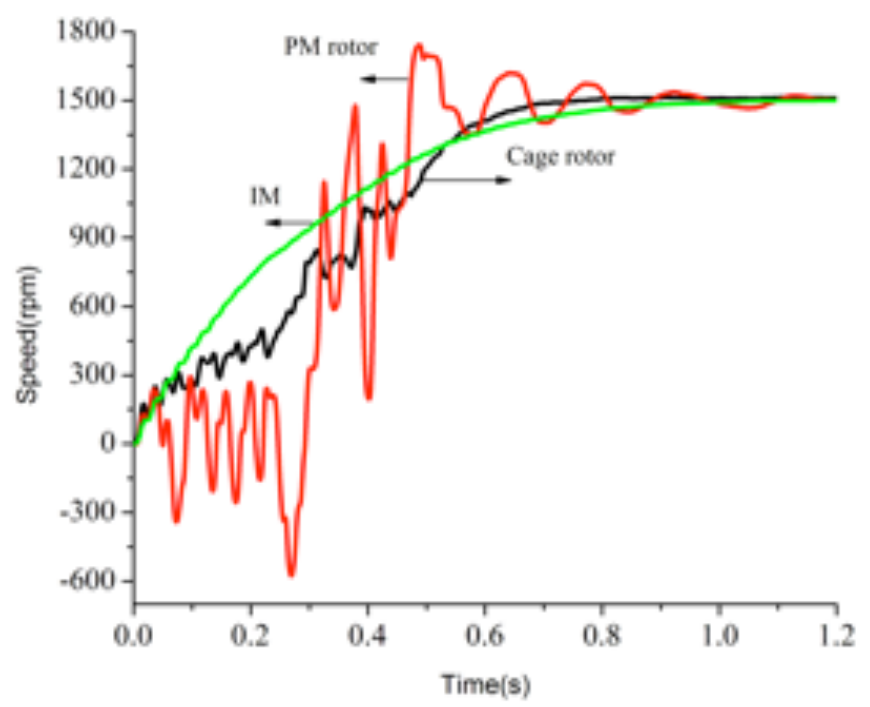

Fig. (4). Comparison of the speed between DRPMIM and IM under no load.

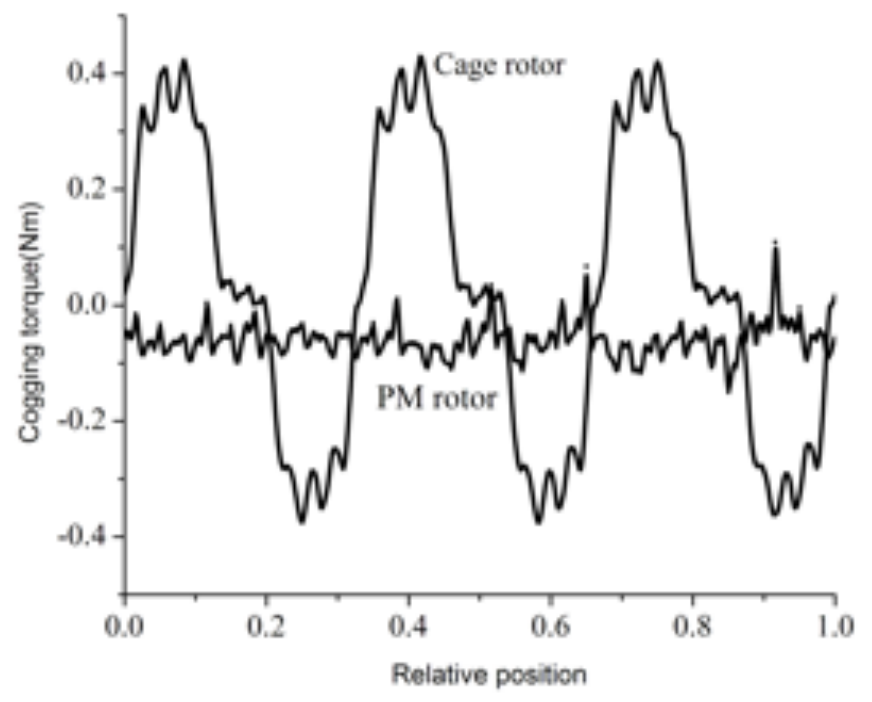

Fig. (5). The cogging torque with outer cage rotor and inner PM rotor.

Because of the interaction between permanent magnet and grooved armature core, cogging torque is generated inevitably. The cogging torque is immanent phenomena in permanent magnet motors. Fig. (5) shows the variation in cogging torque according to the relative position of rotor for DRPMIM.This figure illustrates that the cogging torque of cage rotor has higher magnitude than that of PM rotor. The cogging torque magnitude of cage rotor is $0.42 \mathrm{~N} . \mathrm{m}$. The cogging torque magnitude of PM rotor is $0.05 \mathrm{~N} . \mathrm{m}$.

The inductance of the DRPMIM is calculated by 2D finite element analysis. DRPMIM and IM are both 4 poles squirrel cage. The calculation parameters of two type of motors are calculated as shown below Table $\mathbf{2}$, in which the rotor parameters have been converted to the stator side.
Table 2. Comparison of the calculation parameters between DRPMIM and IM based on FEM.

\begin{tabular}{ccc}
\hline Parameters & DRPMIM & IM \\
\hline Stator resistance $(\Omega)$ & 2.68 & 2.65 \\
Stator self inductance $(\mathrm{mH})$ & 41.29 & 40.4 \\
Rotor resistance $(\Omega)$ & 2.43 & 2.43 \\
Rotor self inductance $(\mathrm{mH})$ & 41.29 & 40.4 \\
Stator and rotor mutual inductance $(\mathrm{mH})$ & 35.19 & 34.19 \\
Permanent magnetic flux linkage $(\mathrm{Wb})$ & 0.5836 & 0 \\
\hline
\end{tabular}

As shown in Table 2, inductance of DRPMIM is slightly larger than that of IM, which is consistent with the 2-D FE flux lines analysis. According to the calculation of inductance parameters above, the simulation model of DRPMIM and IM are established, and the two kinds of motor are compared under no-load and load conditions.

The structure for DRPMIM can be equivalent to the combination of the two motors, squirrel cage induction motor and permanent magnet synchronous motor. As for outside air gap, it is a squirrel-cage asynchronous machine, whose air gaps is evenly. Inside the air gap, it is permanentmagnet synchronous motor with surface-mount type magnets. Regarding the effects, permanent magnetic synchronous rotor(PM rotor) can be seen the equivalent of the constant flux, which is a synchronous speed rotation in the air gap.

Due to internal and external air gap distance is less than the width of the squirrel-cage bar, so most of the main flux may pass through the cage of the motor rotor into the stator yoke, which has been verified by Ansoft simulation results in electromagnetic field calculation as shown in Fig. (3). Therefore, when considering mathematical model, to facilitate analysis, the PM rotor is equivalent to a constant synchronous magnetic flux in the air gap.

\section{DYNAMIC BEHAVIOR OF DRPMIM}

\subsection{Mathematical Model Theory of DRPMIM}

Because the DRPMIM is a high order system with a multi-variables, strong coupling, nonlinear, and timevarying, in order to facilitate the analysis of the problem, the following assumptions are made:

(1) ignoring the space harmonics, three-phase symmetrical windings in stator produce magnet force according to sine distribution along the air gap;

regardless of core loss, ignores the nonlinear magnetic circuit saturation;

(3) ignoring the effect of frequency and temperature on the winding resistance.

Cage rotor and stator are format a asynchronous motor structure, through the three-phase symmetrical current with angular frequency $\omega_{0}$, generating a rotating at synchronous speed magnetic field in the space during normal operation, the PM rotor rotates at synchronous speed, whose magnetic 
chain will also rotates at synchronous speed. Therefore, the air gap flux angle in cutting the stator frequency $\omega_{0}-\omega_{r}$.

The magnets rotor are separated from the cage-type rotor by bearings, so the magnets rotor and cage rotor are rotated at different speeds. The cage-type rotor speed is slightly slower than the synchronized speed. The magnets rotor speed is the same as the synchronized speed because it is no load.

Generally, the rotation of the PM rotor is similar to that of the rotating field synchronous motor with no load. In this kind of motor, the air-gap flux is provided by both rotating permanent magnets and the stator coil current.

From the analysis above, air gap of DRPMIM magnetic field is composed of three parts, namely, the stator magnetic field, squirrel cage rotor magnetic field and PM magnetic field. Permanent magnetic flux of DRPMIM is shown in Fig. (6), $\varphi$ is angle that the PM rotor and the stator flux, $\theta$ is angle between squirrel cage rotor flux and stator flux.

The stator A phase, cage rotor a phase, PM rotor shafting system and $\mathrm{dq} 0$ synchronization coordinate system relational schematic is shown in Fig. (6). As a result of PM rotor rotates at synchronized speed, namely dq0 shafting system rotates at the same speed, therefore, The angle between the axis of the stator phase A and d-axis can be expressed as

$\alpha=\alpha_{0}+\omega_{0} t$

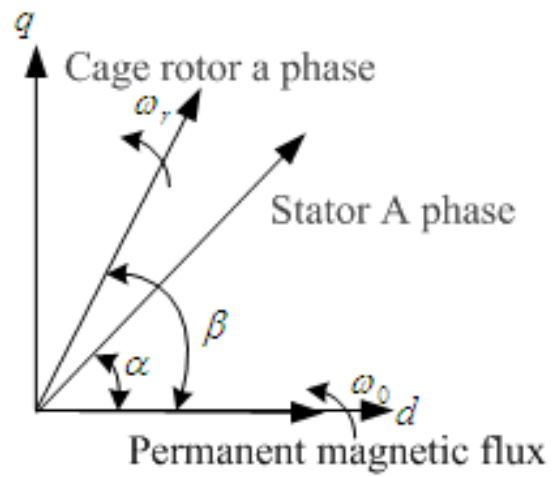

Fig. (6). Relationship between static coordinate system and synchronous reference frame.

Because the squirrel cage rotor rotates with asynchronous speed, dq0 rotating at synchronous speed, the definition of included angle of squirrel cage rotor of a axis and $d$ axis for

$\beta=\beta_{0}+\left(\omega_{0}-\omega_{r}\right) t$

where $\alpha_{0}$ and $\beta_{0}$ are the initial angle, generally, in order to simplify the model, the value is zero.

PM rotor is inside DRPMIM, whose function is equivalent to adding an rotation flux at synchronous speed in the outer air gap. When establish mathematical model, magnetic field of the PM rotor can be modeled as a constant $\psi_{\mathrm{f} 0}$, which plays a role in internal and outside air gaps.

\subsection{Mathematical Model of DRPMIM}

According to the coordinate system above, the voltage equation can be established as the Eq. (3).

$\left\{\begin{array}{l}u_{d s}=p \psi_{d s}-\omega_{0} \psi_{q s}+r_{s} i_{d s} \\ u_{q s}=p \psi_{q s}+\omega_{0} \psi_{d s}+r_{s} i_{q s} \\ u_{d r}=0=p \psi_{d r}-\left(\omega_{0}-\omega_{r}\right) \psi_{q r}+r_{r} i_{d r} \\ u_{q r}=0=p \psi_{q r}+\left(\omega_{0}-\omega_{r}\right) \psi_{d r}+r_{r} i_{q r}\end{array}\right.$

where,

$u_{\mathrm{ds}}{ }^{--}-$the stator $\mathrm{d}$ axis voltage, $\mathrm{V}$;

$u_{\mathrm{qs}^{--}}$-the stator $\mathrm{q}$ axis voltage, $\mathrm{V}$;

$u_{\mathrm{dr}}$---the rotor $\mathrm{d}$ axis voltage, $\mathrm{V}$;

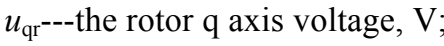

$r_{\mathrm{s}}$---the stator resistance, $\Omega$;

$r_{\mathrm{r}}$---the rotor resistance, $\Omega$.

The flux linkage equation can be expressed as the Eq. (4).

$\left\{\begin{array}{l}\psi_{\mathrm{ds}}=L_{\mathrm{s}} i_{\mathrm{ds}}+L_{\mathrm{m}} i_{\mathrm{dr}}+\psi_{\mathrm{f} 0} \\ \psi_{\mathrm{qs}}=L_{\mathrm{s}} i_{\mathrm{qs}}+L_{\mathrm{m}} i_{\mathrm{qr}} \\ \psi_{\mathrm{dr}}=L_{\mathrm{m}} i_{\mathrm{ds}}+L_{\mathrm{r}} i_{\mathrm{dr}}+\psi_{\mathrm{f} 0} \\ \psi_{\mathrm{qr}}=L_{\mathrm{m}} i_{\mathrm{qs}}+L_{\mathrm{r}} i_{\mathrm{qr}}\end{array}\right.$

where,

$\psi_{\mathrm{ds}^{---}}$the stator d axis flux, $\mathrm{Wb}$;

$\psi_{\mathrm{qs}^{-}}{ }^{--}$the stator q axis flux, $\mathrm{Wb}$;

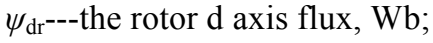

$\psi_{\mathrm{qs}^{--}}-$the rotor $\mathrm{q}$ axis flux, $\mathrm{Wb}$;

$L_{\mathrm{s}^{--}}$-stator winding self inductance, $\mathrm{Wb}$;

$L_{\mathrm{m}}$---stator winding mutual inductance, $\mathrm{Wb}$;

$i_{d \mathrm{~s}^{---}}$the stator $\mathrm{d}$ axis current, $\mathrm{A}$;

$i_{q \mathrm{~s}^{--}}$the stator q axis current, $\mathrm{A}$;

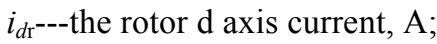

$i_{q \mathrm{r}^{--}}$the rotor $\mathrm{q}$ axis current, $\mathrm{A}$.

In the $\mathrm{dq} 0$ synchronous reference frame, the voltage equations can be converted into the Eq. (5).

$$
\begin{aligned}
& {\left[\begin{array}{c}
u_{d s} \\
u_{q s} \\
0 \\
0
\end{array}\right]=\left[\begin{array}{cccc}
L_{s} p+r_{s} & \omega_{0} L_{s} & L_{m} p & -\omega_{0} L_{m} \\
\omega_{0} L_{s} & L_{s} p+r_{s} & \omega_{0} L_{m} & L_{m} p \\
L_{m} p & -s \omega_{0} L_{m} & L_{r} p+r_{r} & -s \omega_{0} L_{r} \\
s \omega_{0} L_{m} & L_{m} p & s \omega_{0} L_{r} & L_{r} p+r_{r}
\end{array}\right]} \\
& {\left[\begin{array}{c}
\psi_{d s} \\
\psi_{q s} \\
\psi_{d r} \\
\psi_{q r}
\end{array}\right]+\left[\begin{array}{c}
0 \\
\omega_{0} \psi_{f 0} \\
0 \\
s \omega_{0} \psi_{f 0}
\end{array}\right]}
\end{aligned}
$$

where $s$ is the slip of asynchronous squirrel cage rotor. 
Torque of DRPMIM is divided into three parts. They are inner rotor torque $\left(T_{\mathrm{IR}}\right)$, outer rotor torque $\left(T_{\mathrm{OR}}\right)$ and the torque for the motor's electromagnetic torque $\left(T_{\mathrm{S}}\right)$, respectively. They can be expressed as the Eq. (6).

$$
\left\{\begin{array}{l}
T_{S}=\frac{3}{2} p\left(i_{d s} \psi_{q s}-i_{q s} \psi_{d s}\right) \\
T_{O R}=J_{O R} \frac{d \Omega_{O R}}{d t}+T_{L}=\frac{3}{2} p\left(i_{d r} \psi_{q r}-i_{q r} \psi_{d r}\right) \\
T_{I R}=J_{I R} \frac{d \Omega_{I R}}{d t}+T_{0}=\frac{3}{2} p\left(\left(i_{d s} \psi_{q s}-i_{q s} \psi_{d s}\right)-\left(i_{d r} \psi_{q r}-i_{q r} \psi_{d r}\right)\right)
\end{array}\right.
$$

Inner PM rotor inside is the cage rotor, which is not connected to the load. Therefore, the torque of the inner PM rotor torque is generated, which mainly was used to overcome the friction on the rotor shaft. If you ignore the friction force on the rotor shaft, and when the speed is constant, the torque $\mathrm{T}_{\mathrm{IR}}$ is equal to 0 . The outer squirrel cage rotor is connected with the load, when the speed of the squirrel cage rotor is constant, torque $T_{O R}$ is used to balance the load torque.

V Simulation model establishment and analysis based on synchronous rotating coordinate system.

According to the equation above, it can be written $s$ functions in Matlab.The basic DRPMIM mathematical model is set up as shown in Fig. (7).

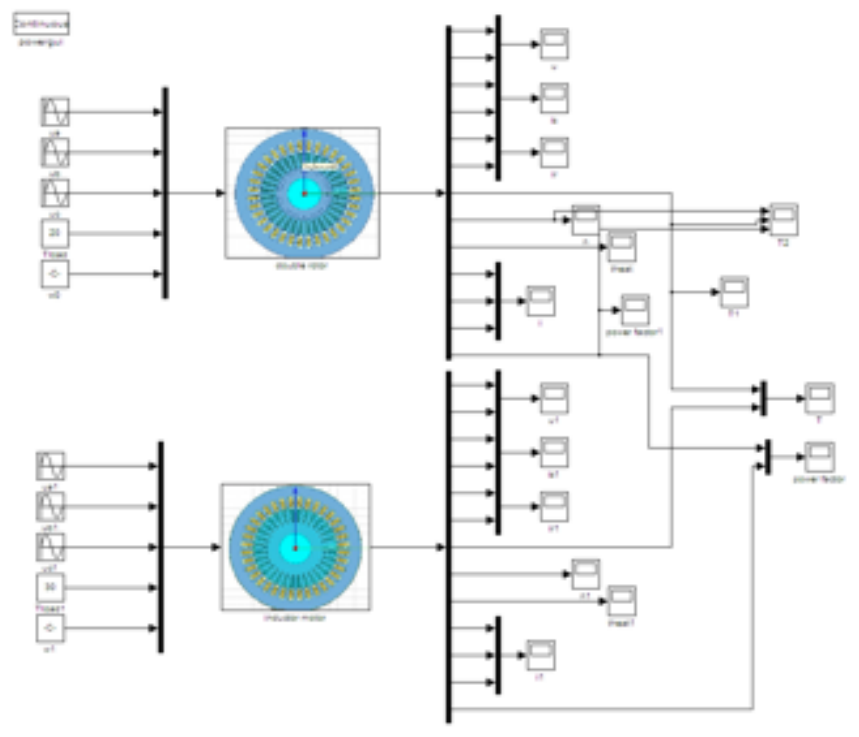

Fig. (7). The simulation model of DRPMIM and IM.

A comparative analysis of the inductance parameters of DRPMIM with the same size, from the analysis above, in essence, there is a permanent magnet rotor inside squirrel cage rotor, the rotor permanent magnet flux linkage of a constant magnetic field, the magnetic field and the squirrel cage rotor the inner air gap coupling; at the same time, through the squirrel cage rotor into the air gaps, and coupled with the stator magnetic field. Therefore, the magnetic field inside the motor is based on the original magnetic field is superimposed on the permanent magnetic field of a synchronous speed rotating. If the gap is equal to air gaps and the squirrel cage induction machine of double rotor motor, due to its internal air gap is a gap, so that the motor increases, the magnetic reluctance of the increase, thereby increasing the inductance parameters of the motor.

Under no load condition, the voltage of the motor is the three-phase $220 \mathrm{~V}$. In this case, the three-phase stator current waveform of DRPMIM and IM as shown in Figs. $(\mathbf{8}, \mathbf{9})$.

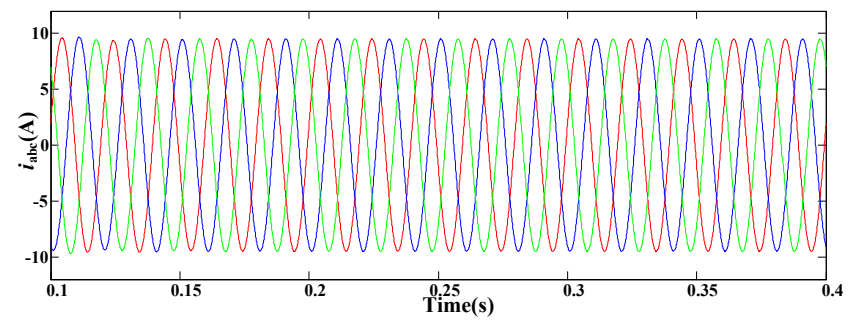

Fig. (8). Three phase stator current waveform under no-load for DRPMIM.

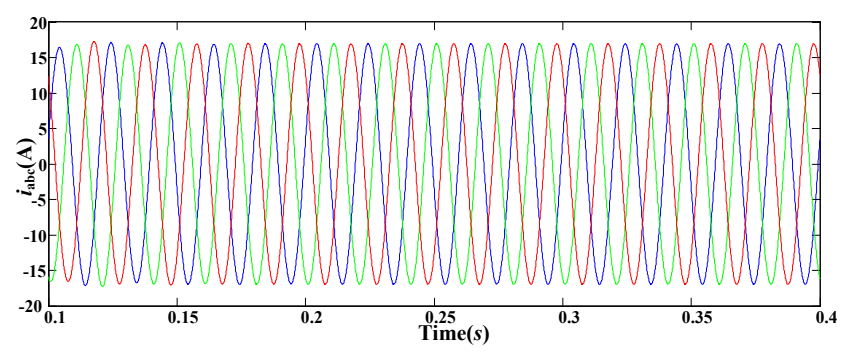

Fig. (9). Three-phase stator current waveform under no load for usual IM.

From Fig. (8) we can see, stator current effective value of DRPMIM is 6.72A under no-load. From Fig. (9), stator current effective value of IM is $11.98 \mathrm{~A}$ under no-load. The stator current of DRPMIM is far less than that of the ordinary IM.This is the result of synchronous rotating permanent magnet in DRPMIM. Under no load, the motor current is the main excitation current. In DRPMIM, the PM rotor will provide a part of magnetic field, namely, the stator current is not required to provide a larger magnetic field, so that the stator current will be greatly reduced. The exciting current is small and low loss, which is the greatest advantages of DRPMIM compared to usual IM.

Under the load condition, power supply to the motor phase voltage is AC 220V.Three phase current waveform and speed of the motors under 20Nm load are shown in Figs. $(10,11)$.

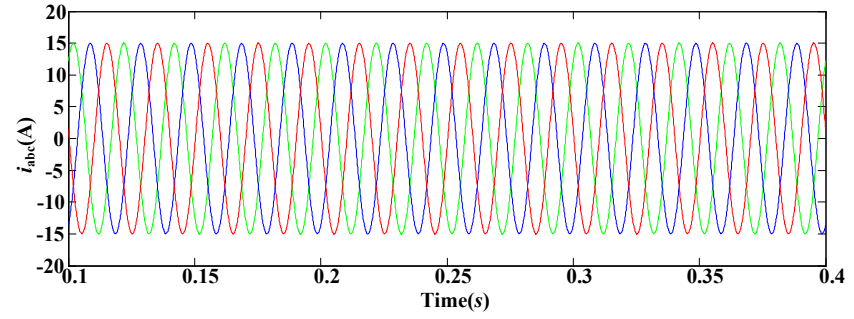

Fig. (10). Three phase stator current waveform under load for DRPMIM.

As shown in Fig. (10), the stator current effective value of DRPMIM is 10.61A under the load; as shown in Fig. (11), the stator current effective value of IM is $14.14 \mathrm{~A}$ under the same load. As you can see, under the same $20 \mathrm{Nm}$ load, load 
current of DRPMIM is less than that of IM. The exciting current of DRPMIM is smaller than that of IM not only under the load but also under no load.

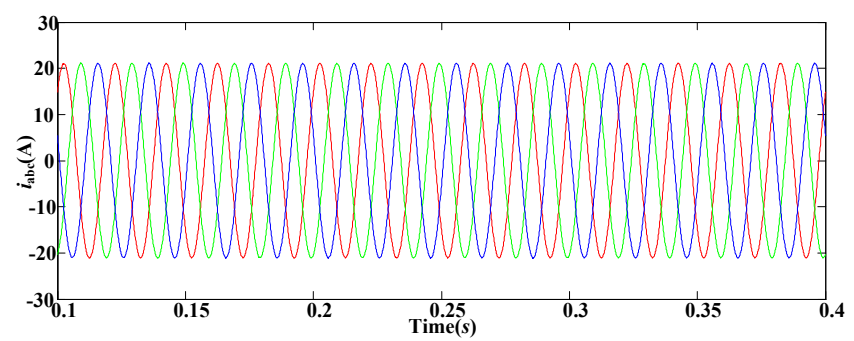

Fig. (11). Three-phase stator current waveform under load for IM.

As shown in Fig. (12), it is the comparison of the power factor between DRPMIM and IM under the same load conditions. The power factor of the DRPMIM is 0.815 , and the power factor of IM is 0.706 . Thus it can be seen, because of the PM rotor, it plays a positive role in improving the power factor of the DRPMIM.Reactive power of DRPMIM needed from electric network is lower than that of IM.

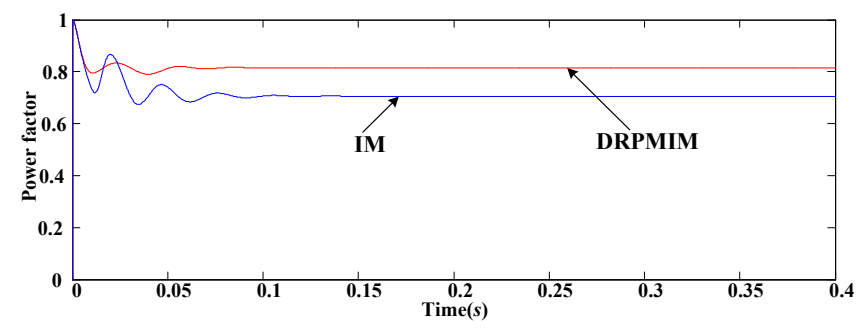

Fig. (12). Comparison of the power factor between DRPMIM and IM.

Comparison of the speed between DRPMIM and IM under the same load is shown in Fig. (13). Stable speed of DRPMIM is slightly higher than that of the IM, and the DRPMIM is more stable in the process of starting. Comparison of the torque curves between DRPMIM and IM are shown in Fig. (14) under the same load. In the stable operation, load torque of two kinds of motors were stable at around $20 \mathrm{Nm}$. Because the friction braking torque is ignored in the motor model, the electromagnetic torque and load torque is finally reached a balance.

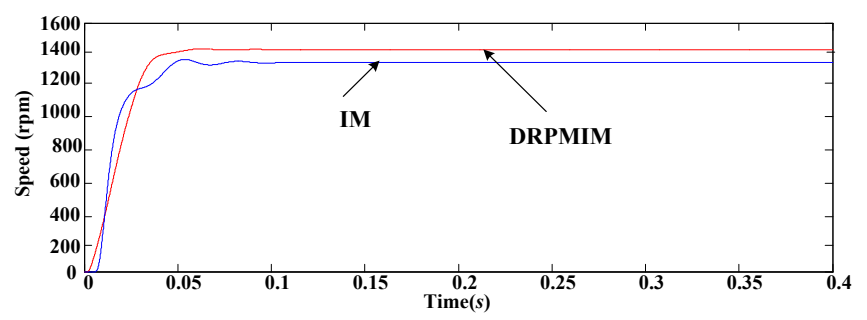

Fig. (13). Comparison of the speed between DRPMIM and IM.

\section{CONCLUSION}

This paper studies and analyzes performances of DRPMIM.In order to realize the electromagnetic characteristics, two-dimensional finite element model of DRPMIM is established by Maxwell software, and electromagnetic characters of that are analyzed. Distribution of magnetic line, the speed curves and cogging torque curves are analyzed and studied by finite element method, in order to to establish precise mathematical model. The key findings and results are as follows:

- The DRPMIM increase magnetic flux linkage in the machine, which can be verified by finite element method.

- The mathematical model of DRPMIM was first established and the corresponding simulation results show power factor is higher that that of usual IM.

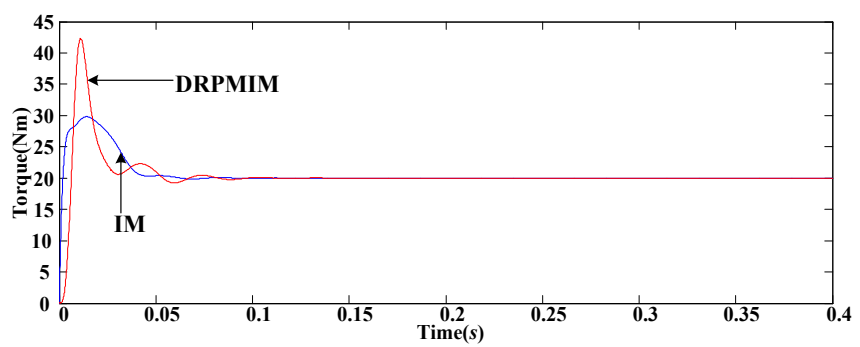

Fig. (14). Comparison of the torque between DRPMIM and IM.

In a word, there are some difficulties in the design and manufacture for DRPMIM, small volume, light weight, but DRPMIM has some advantages, which is suitable for the pump and fan load. Power factor and efficiency are higher than the same size of the ordinary IM. The DRPMIM is in accordance with the demand of social development and energy saving. These results are verified the performances of DRPMIM.Its dynamic mathematical model is established, which is convenient for controlling it later.

\section{CONFLICT OF INTEREST}

The authors confirm that this article content has no conflict of interest.

\section{ACKNOWLEDGEMENTS}

Declared none.

\section{REFERENCES}

[1] R. Qu, and T. A. Lipo, "Dual-rotor, radial wound, permanentmagnet machines", IEEE Trans. Ind. Appl., vol. 39, no. 6, pp. 1665-1673, 2003.

[2] R. Qu, and T. A. Lipo, "Design and Parameter effect analysis of dual-rotor, radial-flux, toroidally wound, permanent magnet machines," IEEE Trans, Indust. Appl., vol. 40, no. 3, pp. 771-779, 2004.

[3] L. Xu, and Y. Zhang, "Design and evaluation of a dual mechanical port machine and system," In: IEEE 5th International Power Electronics and Motion Control Conference, Shanghai, China, 2006.

[4] R. Qu, and T. A. Lipo, "Analysis and modeling of air-gap and zigzag leakage fluxes in a surface-mounted permanent-magnet machine," IEEE Trans Indust. Appl., vol. 40, no. 1, pp. 121-126, 2004.

[5] C. H. Wang, and Y. H. Cho, "Effects of leakage flux on magnetic fields of interior permanent magnet synchronous motors," IEEE Trans. Magn., vol. 37, no. 4, pp. 3021-3024,2001.

[6] R. Qu, M. Aydin, and T. A. Lipo, "Performance comparison of dual-rotor radial-flux and axial-flux permanent magnet BLDC machines," In: Proceedings of IEEE Electric Machines and Drives Conference, Madison, US, pp. 1948-1954, 2003.

[7] H. N. Phyu, C. Bi, and L. Song, "Numerical modeling and performance analysis of a disk drive spindle motor using circuit- 
field coupled systems," In: Asia-Pacific Magnetic Recording Conference, Singapore, pp. 1-2, 2006.

[8] M. A. Jabbar, Z. J. Liu, and D. Jing, "Time-stepping finite-element analysis for the dynamic performance of a permanent magnet synchronous motor," IEEE Trans. Magnet., vol. 39, no. 5, pp. 2621-2623, 2003.

[9] W. N. Fu, and Z. J. Liu, "Estimation of eddy-current loss in permanent magnets of electric motors using network-field coupled multislice time-stepping finite-element method," IEEE Trans. Magnet., vol. 38, no. 2, pp. 1225-1228, 2002.

[10] S. L. Ho, and H. L. Li, "Dynamic modeling of permanent magnet synchronous machines using direct-coupled time stepping finite element method," In: Proceedings of IEEE Conference on Electric Machines and Drives, Seattle, USA, pp. 113-115, 1999.

[11] Y. Shibata, N. Tsuchida, and K. Imai, "High torque induction motor with rotating magnets in the rotor", Electric. Eng. Japan, vol. 117, pp. 102-109, 1996.

[12] Y. Shibata, N. Tsuchida, and K. Imai, "Performance of induction motor with free-rotating magnets inside its rotor", IEEE Trans. Indust. Electron., vol. 46, pp. 646-651, 1999.

[13] T. Fukami, K. Nakagawa, R. Hanaoka, S. Takata and T. Miyamoto, "Nonlinear modelling of a permanent-magnet induction machine", Electric. Eng. Japan, vol. 144, pp. 58-67, 2003.

[14] X. Liu, J. Jiang, G. Yu, and D. Ye, "Simulation of permanent magnet synchronous motor with dual closed loop by time-stepping finite element model," In: Proceedings of IEEE Conference on
Power Electronics and Motion Control, Shanghai, China, pp. 1-5, 2006.

[15] S. Niu, K. T. Chau, J. Z. Jiang, and C. Liu, "Design and control of a new double-stator cup-rotor permanent-magnet machine for wind power generation," IEEE Trans. Magnet., vol. 43, no. 6, pp. 25012503, 2007.

[16] R. Liu, Y. Zhang, M. Hu, and D. Yan, "Field circuit coupled time stepping finite element analysis on permanent magnet brushless DC motors," In: Proceedings of IEEE Conference on Electric Machines and Systems, Nanjing, China, pp. 2105-2108, 2005.

[17] D. Yan, R. Liu, M. Hu, X. Li, "Calculation of transient performance in the PMSM based on the time-stepping FEM," In: Proceedings of IEEE Conference on Electric Machines and Systems, Beijing, China, pp. 819-822, 2003.

[18] M. S. Islan, S. Mir, and T. Sebastian, "Issues in reducing the cogging torque of mass-produced permanent magnet brushless DC motor," IEEE Trans. Indust. Appl., vol. 40, no. 3, pp. 813-820, 2004.

[19] Z. Q. Zhu, and D. Howe, "Influence of design parameters on cogging torque in permanent magnet machines," IEEE Trans. Energ. Conve., vol. 15, no. 4, pp. 407-417, 2000.

[20] R. Lateb, N. Takorabet, and F. Meibody-Tabar, "Effect of magnet segmentation on the cogging torque in surface-mounted permanentmagnet motors," IEEE Trans. Magnet., vol. 42, no. 3, pp. 442-445, 2006 .

(C) Tongshan Diao; Licensee Bentham Open.

This is an open access article licensed under the terms of the Creative Commons Attribution Non-Commercial License (http://creativecommons.org/licenses/by$\mathrm{nc} / 3.0 /$ ) which permits unrestricted, non-commercial use, distribution and reproduction in any medium, provided the work is properly cited. 